\title{
Modern Medicine and Surgery: Physics and War
}

\author{
Simon Raymond* \\ Consultant specializing in Medical and Scientific Research, Australia
}

ISSN: 2578-0379

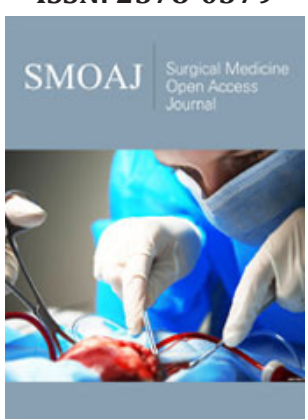

*Corresponding author: Simon Raymond, Consultant specializing in Medical and Scientific Research, Alumnus, Australia

Submission: 侮 May 30, 2019

Published: 笽June 10,2019

Volume 2 - Issue 4

How to cite this article: Simon Raymond. Modern Medicine and Surgery: Physics and War. Surg Med Open Acc J.2(4). SMOAJ.000544.2019. DOI: 10.31031/SMOAJ.2019.02.000544.

Copyright@ Simon Raymond, This article is distributed under the terms of the Creative Commons Attribution 4.0 International License, which permits unrestricted use and redistribution provided that the original author and source are credited.

\begin{abstract}
This publication discusses recent research by the current author. There are both aspects of research in that some is able to be viewed as clinically relevant already such as the new generation immunization program (References ) and the need to check mind related programs (Example I) that have occurred during the war type climate to ensure they provide the quality information that medical research funding agencies expect when used on the description of medical research. and some is in some ways futuristic but still able to be understood as perhaps coming into clinical relevance including the increasing consideration of the need to distinguish a difference (and whether there is a difference) between micro-organism awareness and that of a macro-being and why it should (if it should) still be viewed as appropriate for doctors to use antimicrobials. Furthermore, protection measures in a clinical setting such as measuring the weight of patients to ensure that during the period of uncertainty there is the intention displayed to be treating a macro-being and only targeting micro-organisms in terms of the use of antimicrobials until it is better ascertained as to the topic above regarding clarity as to whether there is continued appropriateness in prescribing antimicrobials with a material difference to that of war and military type attacks on enemies.
\end{abstract}

Keywords: Modern medicine; Macro-being; Immunization

\section{Introduction}

The current author is the researcher who has developed the new antimicrobial pathway site attachment inhibition including new generation immunization (stem cell therapy based). References 1-12 below present this in further detail. The principle purpose of the current publication is to detail the increasing relevance of war to medicine and surgery. The increasing relevance to the physics departments is also discussed. Both medicine and physics have been prestigious fields for some period. USA and Russia perhaps standout as two areas with both medicine and space exploration as key areas of research and development, in addition to both countries appearing as often leaders in the global environment. The application of quantum physics (advanced physics) to medicine and surgery appears to be the future pathway for the profession as detailed by the current author in recent conference proceedings and publications [1-5]. The current author anticipates the increasing interest in physics in the medical faculties as perhaps changing physiology to the study of physics (with biology as a separate branch) as discussed particularly [2].

Physics has already been involved in medicine and war faculties by way of nuclear and other research fields.

There appears to be a more in-depth involvement of physics, medicine and research type faculties in the future of war. Two important examples as an initial starting point are presented below. The reason for Minds as an example is to clearly show structure in that minds has always been considered the highest (most prestigious) level of study (research) in both medical and religious type faculties and also in war. Given Minds appears to be relevant in a war context to the above mentioned faculties then the involvement of such faculties would seem worthy of the time and effort to establish the involvement given the prestigious level that is a strategic match with the prestigious type reputation of the faculties as detailed.

War

\section{Example I}

The following has been accepted for presentation at:

$7^{\text {th }}$ International Conference on General Surgery and Surgical Research Oct 23-24, 2019, Rome, Italy. 
The war climate globally is now stated as, in recent years and ongoing, consisting of not only terrorist type warfare but also official world war type climate, after systematic analysis according to key criteria for assessment of combat type.

The key features present, according to generally accepted criteria, with regards to combat considered characteristic of world war type climate (categorization):

A. Pledges to a leader positioning themselves in a defined manner

B. Mind abuse type programs (mind coding and other)

*Mind abuse programs are carried out for numerous reasons (for example, to achieve robotic following of the given leadership through brainwashing and related abuse)

USA, Britain and others have contained, although perhaps transiently, markers indicating such climate to have been present in such areas. See Reference [1] below. Given the markers, programs run during the years 2009-2016 (in addition to any other periods relevant) should be checked for mind abuse type programs. This would include:

\section{A. Brain Initiative program;}

B. Mind Mapping program, of which both are indexed on NLM, USA National Library of Medicine. An Australian neurosurgeon was involved in the above with the given government members. The programs may be of value but should be checked appropriately. In addition, consideration given to plans for protocol to check other programs if appropriate.

\section{Conclusion}

The typical aspects of world war climate have been detailed along with the reasoning behind such regimes and groups containing such programs including mind abuse directed activities. Furthermore, it is advised that the programs including those detailed are checked to ensure they provide quality medical information for the intended use of the indexing services.

\section{Example II}

There is currently a context of world war type climate in addition to crises internationally regarding infectious diseases. This has, as adjoined, the developing evidence of the awareness of infectious agents [1 -13]. Although infectious agents may not be aware in the same way as macro-being, there is still sensitivities given the world war type climate as discussed in Example I. This means that in addition to ensure antimicrobials only be used on micro-organisms there is also interest in research to ensure that micro-organism awareness isn't the same as macro being and war (or, other) type harshness occurring to such lifeforms. Respect for biology remains important.

Extending on the above, the awareness of infective agents should be taken seriously [3,13]:

A. There is consideration by respected universities regarding awareness of computers and the need to consider whether computers should be provided similar rights to that of human rights.

B. There is merger occurring with the IT industry. Examples include three-dimensional printing of biology.

C. There is support for the opinion that infective agents may contain awareness, and this is detailed in previous publications. It is supported further in this publication by the ability of infective agents to sense surroundings in the contexts of discriminating between self and foreign.

On the other hand, the seriousness of the invasion of the person of the being by micro-organisms must be taken into account. In addition to whether there is any awareness in the intent by the micro-organisms. The evidence in recent research by the current author is as follows:

\section{At present, there is demonstration of the following:}

A. Microorganisms in the CNS performing voltage gated ion channel communications, possibly demonstrating consciousness or at least a level of awareness.

B. An Axis that appears potentially to have been formed (at least in part) by microorganisms from the intestine(s) through to the pituitary gland (gut-brain axis), and notably the pituitary gland is an area around which used to be termed historically as the seat of the soul, or mind. Based on the above, it could be viewed that these two signs (indications) demonstrate the attempted invasion of the mind of the person by another entity, for instance that of the infective microorganisms. The implication of microorganisms in mental illness has been delineated previously by the current author (researcher) in reports listed below in the section titled References. It is worth considering whether a level of total (or, near total) control could be gained by the microorganisms, causing mental illness at the level of psychosis or insanity. The above is worth further investigating.

Future research will look at whether the micro-organisms could also be copying neurological process and whether that is a form of IP theft $[2,3,13]$. Further to the above topics, and reiterating that it is currently a period termed by some as world war type climate, it will be interesting to perhaps further discuss in the future whether there is any relationship between war and medicine based on examples including: USA has had roles in areas of war including that in Israel and such regions and also in regions containing infectious disease issues including Africa [3]. The views of the author are detailed somewhat again below but will be, after further research conducted, delineated in more depth in future publications.

\section{Conclusion}

This publication provides discussion with regards to the recent research of the current author of which there is both: (A) Clinically relevant information in the immediate; (B) Research findings that are somewhat futuristic but still able to be viewed as perhaps of clinical interest. 


\section{References}

1. Raymond S (2019) Site attachment inhibition therapeutics: Ethica considerations Part 2, Euro scion conference on cancer stem cell \& oncology research: Advancement in cancer research prospects of new therapeutic strategies, Seoul, South Korea.

2. Raymond S (2018) Research update on modern medicine and surgery. Molecular Biology Mol Biol 7(3): 1-3.

3. Raymond S (2018) Site attachment inhibition and the application of quantum physics to medicine and surgery. J Human Soc Sci (IOSR-JHSS) 23(1): 8-12.

4. Raymond S (2018) Site attachment inhibition therapeutics: A new mode of action pathway in antimicrobial therapy. International Journal of Engineering Research and Development (IJERD) 14(1): 75-78.

5. Raymond S (2016) $6^{\text {th }}$ International conference and expo on immunology (870 ${ }^{\text {th }}$ Congress) Chicago, USA.

6. Raymond S (2017) Annual conference on microbial pathogenesis, infectious disease, antimicrobials and drug resistance, Toronto, Canada.

7. Raymond S (2016) Development of new strategic pathways for antiviral therapy. J Clin Cell Immunol 7: 5(Suppl).
8. Raymond S (2016) Consciousness and the development of new strategic pathways for antiviral therapy a focused analysis on HIV. International Journal of Sciences: Basic and Applied Research (IJSBAR) 29: 146-154.

9. Raymond S (2016) The development of new antimicrobial pathways combatting the threat of antimicrobial resistance. International Journal of Sciences: Basic and Applied Research (IJSBAR) 30: 22-28.

10. Raymond S (2017) Site attachment inhibition therapeutics: A core summary. Journal of Aids \& Clinical Research 8 (2): 1-3.

11. Raymond S (2018) $12^{\text {th }}$ World congress on pharmaceutical sciences and pharma industries, site attachment inhibition therapeutics: Dealing with association versus causation issues, London, UK.

12. Raymond S (2018) $10^{\text {th }}$ International conference on clinical and cellular immunology, site attachment inhibition therapeutics: Dealing with association versus causation issues, Madrid, Spain.

13. Raymond S (2017) The Role of infectious disease and inflammation in psychiatric illness. Imperial Journal of Interdisciplinary Research 3(1): 510-513.

For possible submissions Click below: 